\title{
Facilitating Learner Self-efficacy through Interdisciplinary Collaboration in Sustainable Systems Design
}

\author{
Dr. Tela Favaloro, University of California, Santa Cruz
}

Tela Favaloro received a B.S. degree in Physics and a Ph.D. in Electrical Engineering from the University of California, Santa Cruz. She is currently working to further the development and dissemination of alternative energy technology; as project manager of a green building design initiative and researcher with the Center for Sustainable Engineering and Power Systems. Her background is in the development of characterization techniques and laboratory apparatus for advancement of novel electronic devices, in addition to curriculum development for inquiry-based learning and facilitation of interdisciplinary, student-led project design. She emphasizes engineering sustainable solutions from a holistic perspective, incorporating analysis of the full technological life cycle and socioeconomic impact.

\section{Dr. Tamara Ball, University of California, Santa Cruz}

Dr. Tamara Ball is a project-scientist working with the the Sustainable Engineering and Ecological Design (SEED) collaborative at UCSC. She is the program director for Impact Designs - Engineering and Sustainability through Student Service (IDEASS) and Apprenticeships in Sustainability Science and Engineering Design (ASCEND). She is interested in understanding how extracurricular and co-curricular innovations can support meaningful campus-community connections in higher education and improve learning outcomes. Her research to date has focused on educational designs that emphasize learner initiative and agency through inquiry or problem-based learning in formal and informal learning contexts. She has published several papers on the characteristics of learning environments that support or constrain opportunities for any students (including those from non-dominant backgrounds) to participate in key science and engineering process skills such as scientific argumentation. Her work is largely informed by the principles and perspectives on human development and cognition articulated by Cultural Historical Activity Theory. Putting theory into practice, she teaches a service-learning course at UCSC wherein interdisciplinary teams of students work in an layered apprenticeship model with community mentors to design and implement sustainable solutions to water, energy, waste, transportation and social challenges using "green technology". Dr. Ball has worked as a research fellow with two NSF Centers for Learning and Teaching and most recently on several NSF projects that focus the integration of engineering and social science to support the advancement of experiential learning for sustainability in higher education.

\section{Mr. Zachary W Graham, University of California, Santa Cruz}

Prof. Michael S. Isaacson, University of California, Santa Cruz

Michael Isaacson is the Narinder Singh Kapany Professor emeritus, professor of electrical engineering, Director of the Center for Sustainable Energy and Power Systems (CenSEPS) and a member of the Sustainable Engineering and Ecological Design Program at UCSC. He is recipient of numerous awards including a Sloan Foundation Faculty Fellowship, the Burton Medal from the Microscopy Society of America, an Alexander von Humboldt Senior Scientist Award, the Rank Prize in Optoelectronics and the Distinguished Scientist Award from the Microscopy Society of America. He is a Fellow of the AAAS and the MSA. He has been elected to the executive board of the Engineering Research Council of the American Society of Engineering Education and is series co-editor of "Advances in Microscopy and Microanalysis" published by Cambridge University Press. He is the PI on an NSF-PIRE grant on "USDenmark Cooperative Research and Education in Intermittency-Friendly Community-scale Renewable Energy Micro-grids". Professor Isaacson has a B.S. in Engineering Physics from the University of Illinois at Urbana-Champaign and an M.S. and PhD in physics from the University of Chicago. He came to UC Santa Cruz in 2003 from Cornell University where he was a professor of Applied and Engineering Physics, director of the Keck Foundation Program in Nanobiotechnology and Associate Dean of Research, Graduate Studies and Professional Education in the College of Engineering. 


\title{
Facilitating Learner Self-Efficacy through Interdisciplinary Collaboration in Sustainable Systems Design
}

\begin{abstract}
An educational partnership between a minority-serving community college and a research university has been offering STEM students an eight-week summer internship in sustainable energy systems with the goal of providing applied research experiences while strengthening community and institutional bonds. In 2015, the interns' involvement in the successful design, development, and implementation of an innovative testbed for assessment of grid supporting "smart" technology was facilitated by early preparations for self-directed learning. Here, we provide detailed descriptions of a phased pedagogical approach that was instrumental in enabling participants from multidisciplinary and diverse backgrounds to effectively communicate, contribute, and innovate. Heavy scaffolding through a series of controlled yet experiential learning activities targeted key engineering content and process skills, while positioning learners to be efficacious during the research and development phase. Participants formed transitional development teams that restructured based on current project needs; each group member took responsibility for becoming an "expert" in self-prescribed roles: wireless communication protocol, residential electrical wiring, embedded systems design and programming, construction technique, research and characterization of "smart" loads, among others.

This paper presents evidence of a) group interaction and individual participation in practices facilitating the collaborative emergence of innovation and b) learner self-efficacy, which we postulate are correlated. Exit interviews, audio diaries, and a survey instrument assessing interactive engagement in learners were used in analyses of the learning processes and learning outcomes of this case study. Findings point to the importance of allowing participants to identify and take ownership of a discrete set of tasks while expanding skillsets and building peripheral knowledge through facilitated collaboration across domain-specific working groups. This case study culminates in a discussion of four constitutive processes of innovation: choice, challenge, accountability, and cross-disciplinary synergy, as being predictive of the learner's ability to participate in collaborative, group-level innovation.
\end{abstract}

\section{Introduction}

Beginning in 2011, Hartnell Community College, a minority serving institution, partnered with a local research university, University of California in Santa Cruz, to cultivate educational pathways that promise to improve matriculation and graduation rates of underrepresented students into the STEM (Science, Technology, Engineering, and Math) workforce. Federal funds granted by the Department of Education supported development of an articulated "community college to university success program" (CUSP) located at Hartnell's newly constructed 
"Advanced Technology" campus, which among other advantages, functions as a living laboratory for research on micro-grid control and integration. The program's holistic approach to workforce development integrates design of sustainability curriculum, student internships, professional training, hands-on technology usage and its implementation; incorporating experiential learning with real world consequence into the classroom. CUSP primarily serves students from the community college and neighboring high schools in the Salinas Valley, and strives to give these students, who may otherwise have minimal access to technological resources and training, the confidence to continue in STEM fields and an edge in the job market upon graduation. Each summer, participants have the opportunity to join multidisciplinary teams working on the design and development of sustainable systems and technologies that support renewable energy, energy efficiency, and resources management.

The CUSP program has implications beyond supporting STEM pathways into higher education; it prioritizes education and training to build a skilled labor force for technical jobs in the expanding renewable energy sector. As the growth of solar and wind energy generation has exploded at a faster rate than a new workforce can be trained in sufficient numbers, there is significant demand for qualified professionals with technical knowledge of energy efficiency and renewable energy. The number of solar related jobs, for instance, grew more than twenty times faster than the overall US economy in 2014. ${ }^{1}$ The Environmental and Energy Study Institute Fact Sheet reported an increase of more than 100,000 jobs related to the solar energy industry and smart grid/demand management in 2014 alone ${ }^{2}$; while surveys identify a specific need for professionals to have problem solving and R\&D expertise. ${ }^{3}$

Organizations both within the United States and internationally, have developed recommendations and strategies to attack the skill gap in the energy industry ${ }^{1,3,4,5}$ :

- Enhance curricula and course content with topics in alternative and renewable energy technology inclusive of industrial energy efficiency

- Improve contextual education in STEM and environmental literacy, especially in K-12

- Utilize instructional technology with access to computerized and industry technology

- Develop energy-related contextual modules for STEM instructor training that target traditionally underrepresented populations

- Establish best practices and training standards for energy educational programs

- Create a clear pathway from K-12 through post-secondary education

With its renewable energy and sustainability focus, this collaborative partnership has the potential to effectively fulfill many of these recommendations and create a pipeline into the workforce beginning at the high school level. Moreover, CUSP specifically designs and makes accessible contextual technology education for learners traditionally underrepresented in the STEM fields. The outcomes of this program can help to establish best practice and serve as an educational training model that can be expanded upon and utilized by other learning institutions. 
This paper discusses results of one particular component of the larger pathway between the partner institutions: the renewable energy summer research internship. Since its inception in 2011, university researchers and graduate students have been collaborating with community college staff to provide daily support and technical mentorship for community college and high school interns over eight weeks in the summer. Students representing multiple disciplines and diverse socioeconomic and cultural backgrounds apply and compete to receive summer stipends through an interview-based selection process, which takes into account a potential participant's GPA, preparation, and learning aspirations. Selected applicants are placed into projects at different sites as appropriate to their skills and interests, where they work under a research mentor from UCSC whose focus is in training students on follow-through and "knowing how,"6 in addition to engineering content. In complement, interns take part in professional development seminars and training hosted by Hartnell College throughout the eight week period. The experience culminates in an oral or poster presentation at a research symposium attended by academic faculty, stakeholders, and members of the community.

In summer 2015, the internship was organized to deliver an innovative deferrable load testbed in support of doctoral research into grid-supporting, demand-side resources. The testbed utilizes hardware-in-the-loop design as a platform for systematic testing of coordinated demand response to simulated grid contingencies. Its development requires a variety of skills and knowledge, encompassing multiple disciplines: computer science (algorithm development and programming); computer engineering (embedded systems design, wireless communication protocol); electrical engineering (power systems and circuit design); residential construction and wiring; physics (photovoltaic characteristics); and behavioral practice. Advancing research into grid-edge technology will help permit higher penetrations of renewable and distributed energy generation resources within the grid.

Students accepted into the internship are expected to take responsibility for primary tasks while working collectively as a team with university researchers as mentors. Yet, student-interns enter the program with a range of formal disciplinary knowledge and skills, but limited experience in applied research and development. To prepare and accelerate the interns' growth in these areas and realize the deliverable within project constraints, we adopted an industry-oriented approach to project management using a hierarchical structure that emphasizes individual responsibility for a (self) specified scope of work. While many "hands-on" classroom learning activities can be highly prescriptive leading students through step-by-step processes; many "learn by doing" internships do little to prevent interns from resorting to trial and error tactics. ${ }^{7}$ By contrast, we structure the CUSP internship around progressive phases of training which function as educational scaffolds ${ }^{8}$ to support learners through development and project implementation. We argue that taking the time to "set them up" in the beginning of the internship and then "let them go" prepares the interns to be more effective in their respective contributions. This pedagogical approach builds on contemporary research in the learning sciences on theories of situated cognition that emphasize how cognition and practice are inseparable; both are contingent on 
social interaction and mediated by the particular symbolic and physical tools being used at any given time by members of the learning community. ${ }^{9}$

\section{Program Design}

In practice, implementing strategies for "setting them up" and then "letting them go" is much more complex than the simple descriptive two phase process. Curricular scaffolds organized around preparatory training goals and close facilitation tactics were applied heavily in the first two weeks of the internship but were continually interwoven through the remaining six weeks to supplement what can be described as an inquiry based pedagogical approach. ${ }^{10}$ Detailed descriptions of program components including the rationale and accompanying pedagogical strategies are presented below as a reference.

\section{Instructional Strategies and Program Planning:}

Overall, the summer internship was designed to support the concerted design and realization of a deferrable load testbed, capable of providing "grid" support through frequency regulation of simulated mains electricity using residential "smart" appliances. The context for this design problem was derived from an authentic research proposal, one that had not been accomplished before (to the best of our knowledge) and would contribute to ongoing, vanguard research into grid-edge technology and distributed energy resources. Mentors anticipated that student-interns would be challenged by their responsibility to deliver an innovative system as part of a larger research endeavor. If successful, participants would emerge with improved proficiency in utilizing process skills and applying disciplinary content, motivating confidence in their own ability to participate in formal science or engineering practice.

An early pedagogic goal was to establish a common knowledge base and technical skillset for student-interns with different experience levels and backgrounds while preparing them to later perform self-directed research and design implementation. According to the supervising mentors, a successful internship would result in evidence of sufficient comprehension of solar photovoltaics, natively generated AC/DC power resources, the definitions of (real) power and reactive (imaginary) power, renewable energy volatility and the effect of its integration on the electrical grid, and energy efficiency in systems engineering. Furthermore, the student-interns would demonstrate improvement in collaborative learning, project management, and engineering design, in particular: communication, professional documentation, articulating milestones, reviewing and synthesizing relevant literature, analytic thinking, and iterative problem solving using "backwards design." To accomplish this, the mentors planned to provide a combination of participatory lectures introducing relevant STEM background and context with task-focused experiential activities that would engage multiple learning styles.

Given the number of interns involved, a single project split into constituent and transitional "development teams" was adopted over the approach implemented in previous years: multiple disparate projects comprised of two or three students each. Bringing students from different 
disciplinary backgrounds together to work on a project that combined and utilized their complementary perspectives was deliberate and considered instrumental to project success. Each participant was expected to become the "expert" of their specific task, allowing teams to restructure wherever their expertise was needed as testbed components were developed. Mentors predicted this inclusive approach would increase interaction between the student-interns both as individuals and as members of development teams. Not only would this structure encourage greater accountability and a sense of ownership for the project among the teammates, but also gives the project a greater probability of success if any one contributing member does not perform as expected. With the problem statement addressed on multiple fronts by the different development teams, mentors could better maintain focus on system-level coordination.

Mentors identified potential topics based on applicant resumes that could be used to organize three subsidiary development teams: programming the master control system as well as the ancillary embedded sensors, smart load characterization and incorporation of renewable energy, and construction of the testbed. Some tasks, such as load characterization, were estimated to take less time or be perceived as less desirable to the interns. Consequently, teams were encouraged to take on two seemingly different topics, with the rationale to ensure responsibilities assumed by each development team would implicate at least one research/process skill and one technical "hands-on" skill.

By predetermining subprojects, mentors could coordinate potential literature and associated starter tasks as resources for interns to begin their respective project work. Mentors speculated that student-interns could be overwhelmed with the ill-defined pathway inherent to backwards design. These starter tasks, defined as mini-projects that employ specific concepts or skills related to the bigger problem on a small scale, would aid in breaking down the larger project into manageable and directed parts that give student-interns a place to begin. Starter tasks are discussed in more detail in the "Let them go" stage.

An additional preparatory strategy, the definition of successive milestones or "tiered goals," was used to support a sense of achievement and success in the event that some project goals were not met. Three major benchmarks were identified, with the first representing a minimum standard or threshold for success and the third representing a more ambitious aim. This stratified presentation of project goals intended to help student-interns comprehend the larger research agenda, self-identify points in which to engage, and provide continuing work as successive milestones were completed. By incorporating stratified and adjustable goals into the program design, mentors would be better prepared to adapt curricular scaffolds and their instructional approach based on unforeseen situations or varying student interest.

\section{Set them up: laying foundational concepts through experiential and team-building activities} As professional engineers, the mentors supporting this summer internship recognized that students are often limited by the learning opportunities afforded them in "teacher-centered" didactic classroom contexts or laboratory exercises characterized by "cookbook" learning 
activities ${ }^{11}$ organized around predetermined outcomes. More specifically, they anticipated that a primary benefit to STEM-learners completing research projects is the confidence to engage in learning activities with indeterminate and unpredictable outcomes. For this internship, the mentors hoped to engage and challenge student-interns by implementing strategies that are neither prescriptive nor the fully unchartered "trial and error" model that exists in the absence of a clear pedagogic plan-but something in between. Details of successive program components designed to achieve this balance are presented below.

\section{Facilitation Strategies and Curricular Scaffolds: the first weeks}

First Meeting $(0.5 \text { hr) })^{*}$ : Mentors endeavored to encourage continuous and communal interaction among the student-interns from the start. The interns were specifically instructed to introduce themselves and include their study area of interest, a description of past internship experiences, and their goals over the next eight weeks.

Setting Expectations ( $2.5 \mathbf{~ h r}$ ): Mentors utilized visual aids to introduce and differentiate this internship's organization from prior learning experiences revealed during the above discussion. They were deliberate to establish the authenticity of the design-problem and the innovative qualities required of a valid solution. The conveyed implication was that student-interns would need to be self-determining and effective in their collaboration, which would require their engagement in the process of scientific inquiry and backwards design to develop a novel solution satisfying given constraints. Expectations for the solution-process were described as:

- Using an iterative approach to develop an optimized solution while identifying and articulating possible trade-offs.

- Understanding the importance of laboratory notebooks

- Producing professional documentation

- Self-guided investigation with heavy interaction with other development teams

Mentors were also careful to clarify their supporting roles and responsibilities, explaining that they would be available to guide, maintain cohesion between teams, and facilitate skill-building; but would not be assuming primary roles as developers. Rather than issue prescriptive procedural commands, they approached discussions of best-practices for the solution-process with the aim of instigating active participation. For example, the topic of a laboratory notebook was presented with open ended prompts to elicit initial suggestions from the interns regarding its importance and utility. Student-interns were engaged in a dialogue about referential content of professional practice (records of design-decisions and progress, preliminary evidence, points of ambiguity, improved collaboration) and the required features are of a "good" notebook (date, title, mistakes, etc.). Preliminary suggestions were recorded in public view (e.g. on a whiteboard) followed by additional suggestions from the mentors. Subsequently, two examples of professional research

\footnotetext{
${ }^{*}$ Rough approximation of time allotted for each exercise
} 
notebooks were presented and student-interns were asked to identify both the positive and negative aspects of each. As a last step, a handout with formal guidelines was available for reference. $^{12}$

Introduction to the Problem Statement (4 hr): A two part lecture series on power engineering served to familiarize student-interns with the problem statement: the volatility of renewable power generation leads to instability in the grid, where unplanned generation increases the utility frequency and an unplanned cutout bogs down the grid, decreasing frequency. Therefore, frequency is an indicator of the relative health of AC mains power. Not all student-interns had a familiarity with circuits beyond a class on introductory electricity and magnetism; the subject of power systems engineering was relatively unknown. The first lecture introduced relevant concepts, beginning with the basic definition of power and building sequentially to cover alternating current and phase, reactive power, and power factor. The second lecture addressed the global problem perspective and its context: how the electrical grid works, the purpose and response time of peaker plants, current grid-edge technology, and the potential roles of smart demand and deferrable loads. Wherever possible, student-interns were encouraged to participate either verbally or by writing on the board. For instance, while displaying the day's outlook of the California Independent Systems Operator's supply and demand with renewables generation, ${ }^{13}$ the mentors posed the question to the interns: "what do you think will happen if it gets cloudy and solar generation cuts out?"

Introduction to the Problem Statement, Part 2 (8 hr): Comprehensive review of selected articles directly relevant to the problem statement assisted student-interns in recognizing the need for the testbed and helped to articulate its function. The journal articles were read as a group, with the pedagogical aim of building a knowledge base while modelling the critical analysis of peer-reviewed literature, with the added benefit of strengthening relationships between the students. The mentors identified and assigned two pertinent journal articles as reading material, with instructions to note interesting or relevant information and concepts that were not clearly understood for a subsequent group discussion. Facilitated reading and review of the $1^{\text {st }}$ article ${ }^{14}$ as a group focused on identifying gaps in knowledge and encouraging interns to identify potential areas for their research. Questions or observations were addressed as they arose, not only verbally, but with relevant diagrams and an impromptu mini-lecture on the different electrical components. Additionally, mentors remarked on the logic presented and potential biases that authors relied on to make their claims. The $2^{\text {nd }}$ journal paper ${ }^{15}$ was read and analyzed in development teams (after they were formed), as mentors drifted between the teams and facilitated internal discussions.

Forming Development Teams (2 hr): Many of the preceding strategies were intentionally delivered to allow the student-interns to recognize and categorize subsystems of the testbed and facilitate the self-determination of tasks within respective purviews based on their own interests, experiences, and goals. Discussions of the research outcomes of the $1^{\text {st }}$ journal article provided a framework to reiterate the problem statement in much more detail. Subsequently, student-interns 
were able to identify constraints and understand their implications on potential testbed circuitry and from this propose the form of a possible solution. To give the interns a more complete overview, mentors presented the different functionality and use cases for the deferrable load testbed based upon the tiered goals established in the planning stage. The student-interns collaboratively identified research areas that were required for a successful deliverable which they used to arrange themselves into their initial development teams. Individual student-interns defined their anticipated roles and determined tentative scopes of work; these roles and responsibilities encouraged ownership over tasks as teams later reformed around current project needs. These early roles are presented in Table 1, corresponding to the student's major and categorized by initial development team.

Table 1: Initial development teams by team name and their group-level responsibilities as of the first week of the internship. Group research areas are subdivided into different scopes of work and labeled by academic major. Also shown are the home institutions, where CC: Community College, RU: Research University, and HS: High School

\begin{tabular}{|c|c|c|}
\hline \multicolumn{2}{|c|}{ Team Name and Academic Major } & Responsible For: \\
\hline \multicolumn{2}{|c|}{ "You've got problems, we've got } & Load Characterization and PV equipment \\
\hline CC & Chemistry & Research safety protocol, grid and PV power generation \\
\hline RU & Electrical Engineering & Relay control and load protection, appliance usage behavior \\
\hline Solar and Generator Energy System & Test bed Construction and Wiring \\
\hline CC & Mechatronics & Mechanical systems: wiring the photovoltaic and load sensors \\
\hline CC & General Engineering & Residential wiring and breaker box; load modification \\
\hline \multicolumn{2}{|c|}{ IT Hertz } & Embedded Sensor Nodes, Data Handling, System-level \\
\hline CC & Electrical Engineering & Programming the single board computer and interfacing the API \\
\hline CC & Computer Science & Data handling and programming the single board computer \\
\hline HS & Undecided (Physics) & $\begin{array}{c}\text { Historical data of weather patterns and load usage; probabilistic } \\
\text { model }\end{array}$ \\
\hline
\end{tabular}

Soldering Workshop ( $3 \mathrm{hr}$ ): A soldering tutorial was introduced as a counter point to the literature intensive and began the hands-on component of the internship. Each student watched a live demonstration and explanation of the different soldering/desoldering techniques, and attempted to solder a through-hole component onto the wireless receiver board for later use.

Literature Review Tutorial $(\mathbf{1 . 5} \mathbf{~ h r})$ : The session on performing a literature review was run very similarly to the laboratory notebook tutorial described above. The mentors gave each student team seed literature for their respective topics to begin their literature reviews, along with a handout differentiating primary from secondary sources. Each development team's initial literature review period varied in duration, though three half-days were reserved for it. 
Solar Photovoltaic Characterization Laboratory (2.5 days): This experiential activity eased student-interns into an inquiry-based approach to research and problem solving. Student-interns would use both inductive and deductive reasoning to better understand a known learning outcome: the need for active load matching due to variations in electrical generation. Concurrently, they would improve upon skills relevant to the success of the internship. After a lecture on the physical mechanisms of photocurrent generation and characteristics of solar cells, students worked in their development teams to explore the effect of varying incident radiation on maximum power point. Instructions for this activity were given in the form of a worksheet which clearly articulated: the required calculations and graphs, topics for discussion in their report and during presentation, tips, and additional bonus investigations. The actual procedure explaining how to perform the appropriate measurements had to be extracted from a partially-written laboratory report. Thus, interns had an "Introduction and Background" available to them for reference and a "Procedure" with circuit diagram to follow, but had to complete the missing sections, for instance, "Data Analysis and Discussion." This approach illustrated a pertinent concept while introducing investigative and group work dynamics in a familiar prescriptive "laboratory" format but was designed to provide instructional aids that supported multiple learning modalities.

Facilitation Strategies and Curricular Scaffolds: the project development phase Individual/Development Team Tutorials (as needed): The mentors provided tutorials customized to the particular needs of the group, the individual development teams, or the individual student researcher over the course of the project development period. Some topics included:

- Phasors

- Computer Programming Architecture (microcontroller)

- Designing programs with flowcharts

- Thermal characterization and transient decay

- Microsoft Excel

GRID Alternatives Solar Panel Install (2 days): This activity would familiarize the studentinterns with residential wiring and photovoltaic system componentry, while also providing access to subject matter experts. Grid Alternatives* is a non-profit organization that provides residential solar photovoltaic systems for low-income families and associated technical training to underserved communities. As part of their service mission, they utilize volunteer labor to install solar power systems on the residences. Early in the internship, we arranged for the students-interns to participate in a two day solar panel install on two houses in the local community. Along with newfound technical knowledge, student-interns benefitted from

\footnotetext{
${ }^{*}$ http://www.gridalternatives.org/
} 
increased confidence in "knowing how" resulting from the completion of a system level project from start to finish (without design work), while building team comradery.

Formulating an Abstract, Thinking Exercise (1-3 hr): In preparation for the project presentations, mentors prepared a handout with directed questions designed to guide the studentinterns in articulating the "why" of the project: what was their motivation and reasoning behind their design concept? These questions and directives urged student-interns to look at their work from a systems level view, while identifying trade-offs and limitations of their proposed solution. Ideally, each response should concatenate into their abstract.

Practice Presentations (1 day): Practice presentations, scheduled half-way through the internship, compelled students-interns to articulate their problem statement and contextualize their work. The interns participated in a social with another internship group (from the CUSP program) as an opportunity to learn about other student projects while communicating their own work to others. Later in the day, they presented their projects and learning accomplishments to a group of local high school students interested in pursuing STEM majors.

\section{Let Them Go: Project Development Stage}

The mentors opted to follow a format loosely based on current industrial practice: the development team members would report to an alternating team lead who in turn provides the project manager and client a synopsis of their team status. As the internship deliverable would continue on to support doctoral research at the university, a graduate student involved with the project assumed the role of client, while the other mentor worked as project manager and kept track of progress, timelines and the next wave of tasks. The student-interns would then be able to discuss their solutions directly with the intended user and not only receive quick feedback on ideas, but also contribute to the formulation of its end usage capabilities.

In reality, this format simply entailed a required daily status summary delivered by a member from each development team every morning before beginning the day's work. This practice was referred to as a "two-minute introduction," where the interns were instructed to stand up in front of the group and cover three topics: yesterday's progress, any problems or issues with which they are currently struggling and their goals for the day. The "team lead" alternated daily among the current group members, as did the order in which each development team would present. The "two-minute introduction" was integrated into the internship during the Solar PV laboratory without the interns being aware of it, though it was explicitly stated that it would be a required practice. Approximately half way through the internship, the mentors began supplementing their questions and comments with time management phrases: How long will that task take? Will you complete it before lunch? The objective was to get the interns to begin thinking about tasks and milestones in terms of priority and to quantify timelines.

In general, this practice was very beneficial to the students and achieved its pedagogical aims; it kept all teams apprised of other teams' progress and thus be more integrated, helped to solidify 
goals, and provided a focal point to gather their thoughts and enter a working mindset at the start of each day. The act of voicing problems aloud usually compelled interns to think about them critically and thus frame a solution, though, having input and alternate views from other teams certainly helped. As anticipated, these sessions usually lasted much longer than the allotted two minutes each.

Mentors recognized that beginning the self-directed, project design and implementation stage could be challenging for the interns and predicted difficulty in determining where and how to transition from the planning phase to constructing a concrete deliverable. To avoid this potential obstacle, starter exercises were proposed for the development teams and also for individual interns, based on their prescribed roles and interests. The following is a brief description of these projects:

Load characterization group mini-projects:

- Analysis of their home electricity bill and energy usage of specific appliances and devices using Kill-A-Watt electricity usage monitors.

- In depth analysis (with a mentor) of the journal article: "An Evaluation of the Water Heater Load Potential for Providing Regulation Service."16

Construction group mini-projects:

- Familiarization with National Electric Code and residential wiring standards

- Grid Alternatives service learning experience

Sensor network group mini-projects:

- Python "Hello World" program in Linux

- Visualization of wirelessly transmitted Kill-A-Watt data

- Precise frequency sensing by zero-point crossing *

- Microcontroller actuation: turn LED on/off in response to voltage level*

In addition, a separate but parallel activity was made available for interns if they felt stuck, were experiencing frustration, or simply needed a brief change of pace. As part of the project entailed characterizing power consumption of different appliances, Kill-A-Watt plug load electricity monitors were employed for data collection. The interns (and mentors) could work on converting these meters from a digital data display to wirelessly transmit data at two second intervals. The

\footnotetext{
${ }^{*}$ Mini-projects assigned to an individual student-intern
} 
project required multiple units, so the task was always available whenever a break was needed from the main project or if an intern wanted to work on their soldering skills.

\section{Methodology: Assessment of Innovation as a Process}

We assessed the overall impact of the internship as a learning intervention to support multidisciplinary group participation in innovation and individual learning achievements by applying three different instruments: a) an exit survey focused on relationships between emergent group-dynamics and evidence of innovation-in-practice b) regular "audio-diary" journal entries recorded by participants in response to a weekly repeating prompt c) focus group exit interviews that prompted participants to not only reflect on what they had gained from the experience but challenged them to provide an accurate and valid explanation of their work process and project deliverables. Our methodology triangulated the different data collected to validate themes present in each instrument and deepen overall conclusions.

The approach used here expands on an analytic framework originally developed by educational psychologists (Hilpert \& Husman) which examines "the underlying latent factors of collaborative emergence, a concept that describes how classroom groups function from a complex systems perspective." 17 The authors explain how they have used their framework to "assess the emergent characteristics of student groups in engineering classrooms and examine them in relationship to student engagement and student innovation." In references 17 and18, Hilpert and Husman define and validate two constructs as central to their analysis, summarized as: Complexity, the perception of diverse group composition established through group communication and interaction to achieve equilibrium; Adaptivity, the collaborative and/or cooperative division of labor and group synergy that implicate group organization and cohesion.

Innovation is framed as a central characteristic of emergent phenomena, the output of an evolutionary process where non-ideal solutions are replaced by more effective ones. We applied these constructs in the interpretation of data in our own analysis of innovation-in-practice facilitating group-efficacy. Furthermore, we strived to better understand and contextualize the individual learner's role in the group process and how their individual engagement might relate to target learning outcomes.

\section{Exit Survey}

The exit-survey implemented in this study was adapted from Hilpert \& Husman's Innovative Engagement Scale, ${ }^{18}$ which was developed to "measure interactive engagement in classroom based research in post-secondary engineering education." The validity of this instrument is wellestablished and has been used to describe innovation emergent from system level interactivity among groups of learners using bivariate correlations with over 1400 respondents in 23 different engineering classrooms in higher education. Typically the instrument is used to relate classroom learning, instruction, and achievement to emergent properties of teamwork and academic outcomes. Modifications to the original survey instrument were required to accommodate differences in the educational context of the study. 


\section{Audio Diaries}

Online freeware and software available on participants' personal mobile devices were employed to support collection of audio-recordings (a.k.a. audio-diary entries) following repetitive prompts that were designed to elicit respondent's changing understanding of the problem context for the system they were involved in designing. Respondents recorded their current understanding to iterative versions of two basic prompts:

- What is your understanding of the problem this project is trying to solve?

- What is your role or task in the project?

\section{Field Notes and Exit Interviews}

In the last week of the internship, the second author went on-site to act as a participant-observer. As part of this evaluation, focus-group and exit interviews were conducted with the interns and their mentors to collect more in-depth qualitative evidence of participant learning and experience in the program. Protocol for focus-group interviews with the interns emphasized eliciting further data regarding: a) their understanding of the problem context b) assumptions about the problem context or purpose of the work c) overall impact of the program on their learning experience in relation to prior classroom-based learning and their future education and career planning. Separate protocol for interviews with the university program mentors prompted: a) descriptions of the overall program design b) pedagogical strategy c) challenges regarding implementation of their educational designs into practice d) reflections on lessons learned and implications for future practice.

\section{Results}

The completion of an engineered system for the assessment of grid supporting "smart" technology within project constraints is concrete evidence of the successful internalization and subsequent application of content and process knowledge. The internship deliverable introduces

fine-grain control and reproducibility for testing of potential deferrable appliances in response to frequency excursions in a simulated mains voltage, which until now, was only performed in situ on the existing power grid. Refer to the block diagram of the deferrable load testbed (Figure 1). 


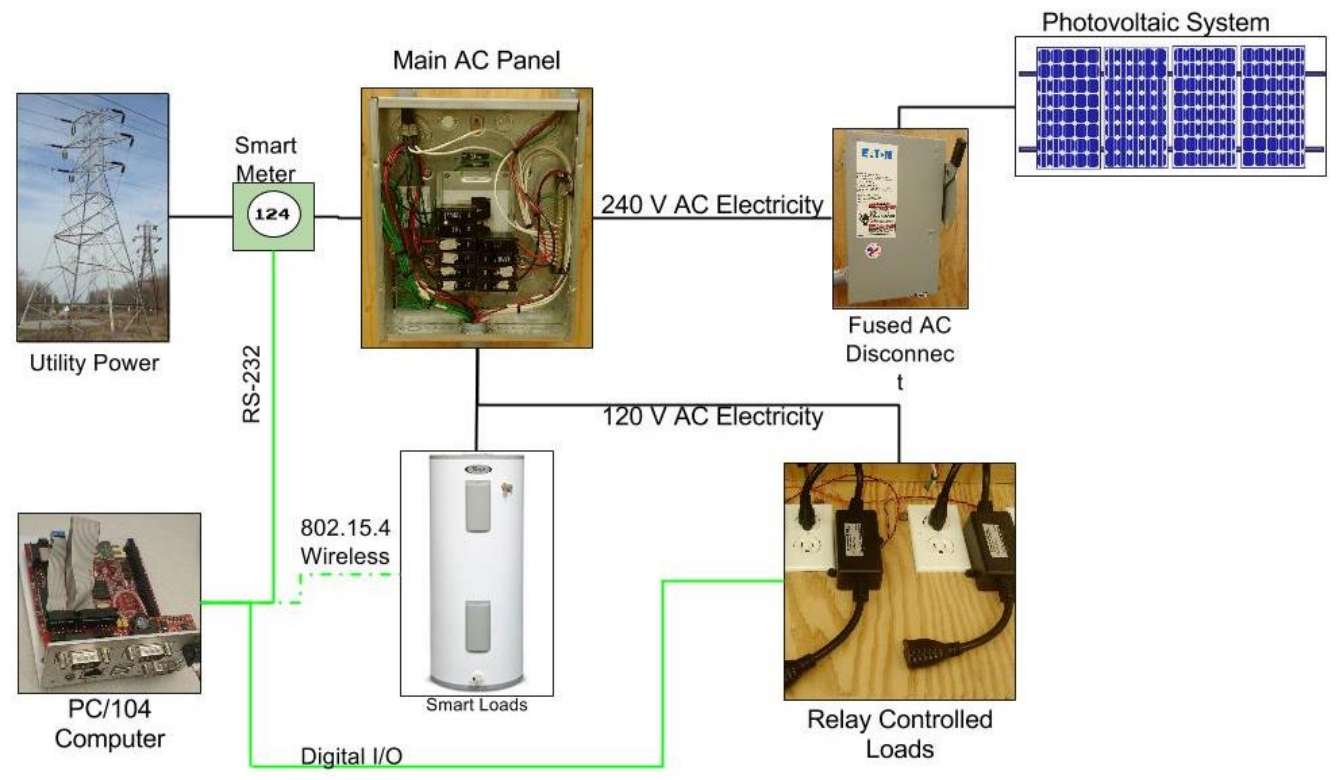

Figure 1: Block diagram depicting the components of the deferrable load testbed

The testbed models a residential load center constructed to safely integrate solar power generation with a high inertia power source. Three subsystems reflect the three development teams and are indicative of the multidisciplinary nature of the project: residential electrical wiring, embedded system design and programming, and smart load development. The breaker panel features six branch circuits with integrated computer-controllable relays for general appliance control. A "smart" water heater with embedded logic was designed and characterized by the student-interns to have defined behavior based on typical water heater usage cycles. Alternative smart appliances were characterized for future implementation (refrigerator and battery bank). The testbed computer platform was designed to easily incorporate new loads and scenarios by being made modular; loads and sensors were configured in a star topology to communicate wirelessly with the local hub. In this way, new smart loads can easily be inserted for testing as they are being developed. The student-interns were able to complete a presentation version of the testbed for demonstration in symposia and laboratories at the research university, where loads turned on/off under priority sequencing in response to a forced disturbance event. The deferrable load testbed has since become integral to ongoing projects at the research university; it is evolving into a developmental laboratory space to further investigation into gridedge technology.

The real-world nature of the project and its deliverable, in addition to self-reported data from the assessment instruments, satisfy criteria ${ }^{19}$ for student outcomes articulated by the Accreditation Board for Engineering Technology for undergraduate engineering education, i.e. the ability to:

a) Apply knowledge of mathematics, science, and engineering

b) Design and conduct experiments, analyze and interpret data 
c) Design a system, component, or process to meet desired needs within realistic constraints

d) Function on multidisciplinary teams

e) Identify, formulate, and solve engineering problems

f) Understand professional and ethical responsibility

g) Communicate effectively

h) Use the techniques, skills, and modern engineering tools necessary for engineering practice

In addition, the student-interns learned to "apply knowledge of contemporary issues" regarding sustainability and "understand the impact of engineering solutions" in a wider context.

The realization of an operational testbed from design to full implementation further evinces emergent group-efficacy in the practice of innovating, which has implications for the learning outcomes of the individual. Self-reported data collected over the course of the internship, as well as participant reflections at the end, provide evidence (presented below) of collaborative emergence as defined by Hilpert and Husman, ${ }^{17,18}$ enhanced by multidisciplinary interaction. Moreover, these responses suggest student-interns experienced increased perceptions of their own self-efficacy as a direct result of their collaborative engagement in an innovation process. In our discussion of these findings, we unpack the larger construct of self-efficacy to show how it encompasses four themes that were prominent in our analysis of learning outcomes. We then postulate that individual participation in the operational processes of innovation correlates to supported perceptions of self-efficacy

\section{“Collaborative emergence" of innovation as a group process}

We applied the criteria defined in Hilpert and Husman's Innovative Engagement Scale to assess characteristics of group interaction that are predictive of innovation. All three data collection instruments exhibited both direct and indirect evidence of group-level collaborative emergence in the form of the constructs complexity and adaptivity. Direct evidence was observed in responses to prompts specifically targeting interactive engagement while indirect evidence was inferred from the evolving self-reflections on the interns' respective roles.

Hilpert and Husman have previously reported survey results as statistical averages of the core constructs they use to characterize interactive engagement in the engineering classroom and the instructional approaches that support these outcomes. ${ }^{18}$ These descriptive statistics for the national averages of the Likert scale items are presented in Table 2 for comparison with the results of this study. 
Table 2: National averages of Complexity, Adaptivity and Innovation in engineering classrooms for comparison with results from this study. Data used to quantify innovation in instructional approach is also presented.

\begin{tabular}{l|ll|ll}
\hline & \multicolumn{2}{|l|}{ National Average (Hilpert \& Husman) } & \multicolumn{2}{l}{ Renewable Energy Internship } \\
\hline & Mean & Std Dev. & Mean & Std Dev. \\
\hline Complexity & 4.54 & 1.70 & 5.86 & 0.609 \\
Adaptivity & 4.30 & 1.71 & 5.88 & 0.194 \\
Innovation & 3.80 & 1.75 & 5.62 & 0.348 \\
\hline Combined Average & 4.21 & 1.72 & 5.79 & 0.384 \\
\hline Instructional & 3.22 & 1.82 & 5.33 & 0.463 \\
Approaches & & & & \\
\hline
\end{tabular}

The combined average is the collective indicator of collaborative emergence, student engagement, and perception of innovation. The value associated with the renewable energy summer internship is nearly a full standard deviation greater than the national average established from studies of student interactions in formal engineering classrooms. By comparative analysis, it is clear that the student-interns' responses are indicative of participation in innovating as a group process. Interestingly, the average response of the student-interns to categorical innovation is greater than one standard deviation of the mean value reported in reference 18 for their larger data set. A possible explanation for the seemingly strengthened "innovation" of this study may be related to the application of a more innovative pedagogical approach, again signified by the greater mean value referencing "instructional approaches" relative to the national average. When analyzing the sub-categories characterizing the stratified instructional approaches (defined in reference 18) assessed by the survey, the method presented here scored higher in all fields but one: the "Lecture" format. In future work, applying this instrument at different points during the internship during/after significant learning activities will give a better indication of the evolution of these processes.

\section{Qualitative evidence of the emergence of Complexity, Adaptivity and Innovation} In addition to the quantitative evidence presented in Table 2, we found supporting evidence of emerging complexity and adaptivity in our qualitative analysis of free-response survey items, biweekly audio-diary recordings, and exit-interview data. In contrast to summative data collected at the end of the internship, analysis of successive entries recorded in the audio diaries revealed how the different dimensions supporting collaborative innovation were actually unfolding over time. We observed increasing differentiation in the articulation of the problem context by each of the seven interns; successive recordings revealed increasing discernment and discretization in their individual understanding of specific requirements and constraints implicated by the problem-solution. We argue that this developing divergence reflects the parallel emergence of diverse expertise among members of the group, role differentiation and the articulation of a robust division of labor indicative of a transfer of ownership across disciplines. Here, we compare and contrast selected excerpts recorded by three of the seven student-interns that exhibit their ongoing engagement in innovation as a function of the emergence of the subthemes of complexity and adaptivity defined by Hilpert and Husman. 
At the end of the first two weeks of the program each of the seven student interns provided comprehensive yet fairly undifferentiated accounts of the problem context. They all described the need to detect and regulate fluctuations or "spikes" in frequency which occur when renewable energy resources (wind, solar) are incorporated with the existing power grid. They all understood that these fluctuations needed to be regulated back to the U.S. standard of $60 \mathrm{~Hz}$ and explained why household appliances capable of storing thermal energy were top candidates for advancing or deferring consumption to accommodate these frequency excursions. There was also evidence that all seven interns assumed that the development of "smart loads" was contingent on the development of infrastructure for a sensor network that could accurately sense, record, and transmit data in real time.

As the internship progressed, the focus of the individual interns' narratives began to specialize. For example, halfway through the summer, comments recorded by 'Antonio' were focused more on the methods for "automated" frequency detection and how to leverage existing Arduino libraries to develop code for issuing commands. By the end of the eight week period, Antonio understood that testing his solution required "setting up the function generator to make sure [he was] recording the correct frequency in the first place."

Early audio-entries recorded by 'Joey' indicate that he was initially well-aware of aware of the need for an automated system for frequency regulation. After four weeks of work on the project his narrative evolved from validating schematics for physically constructing, mounting, and wiring the hardware required to power the system as a residential unit to the problem of understanding and wiring in deferrable loads safely. By the end of eight weeks, Joey focused his discussion on more subtle concepts of constraints on the system, related to the behaviors of the user and prolonging the life of the household appliances: "these are not just automated loads themselves, we need to research when these loads are going to be in use."

Comparisons of the accounts provided by Joey and Antonio are indicative of the emergence and development of their increasingly divergent expertise and a clear division of labor within the team resulting from a transfer of ownership. Moreover, we found strong evidence of collaboration and cooperation among members with highly differentiated roles and the corresponding development of group cohesion and synergy. For instance, 'Juan' stated:

"The other thing that I feel is part of my project is communicating [with] the person... that is doing the hardware - which is focusing on the actual circuitry of the system and understanding how is that going to affect the software too. On the other side, I am working with Kyle [who] is working with the intelligence side of the software and what programming language we need to use to make decisions faster - what kind of data do we need to analyze."

These subthemes (in italics), defined by Hilpert and Husman, ${ }^{17,18}$ can be taken as evidence of interactive complexity and adaptivity and are thus predictive of innovation; their prevalence is further corroborated by statements accumulated in the summative assessment instruments. Juan's developing assumption that he was not only accountable for completing his own tasks but for 
collaborating with his teammates and coordinating their work is in complement to the openended survey responses (Figure 2) reflecting a "collaborative division of labor" and "group synergy." As shown in the figure, aggregated responses from all seven participants explicitly aligned with the six subthemes of complexity and adaptivity. Given that four open-ended questions were specifically coded for evidence of these subthemes, we could expect to elicit at least some evidence of their presence in the twenty-eight responses. As it was, we found "targeted" responses (blue) provided validating affirmations in addition to "unsolicited" evidence in entries from two additional open-ended prompts (red). Refer to Figure 2 for the histogram of the distributed responses by subtheme.

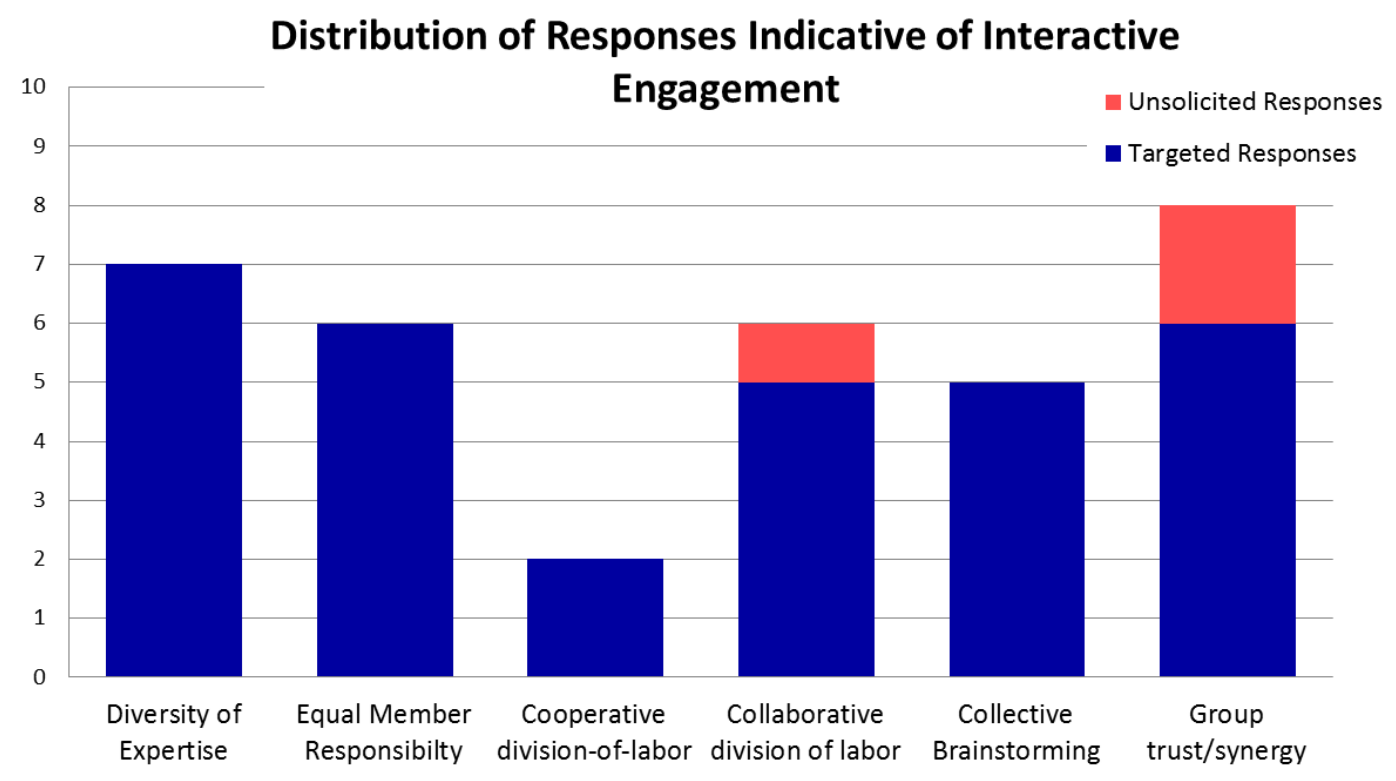

Figure 2: Histogram of the open-ended responses to the survey instrument showing explicit evidence of the subthemes of complexity and adaptivity. Number of respondents: 7 .

\section{Self-efficacy as a learning outcome}

As Hilpert and Husman have previously indicated, evidence of productive participation in grouplevel innovation can be an important predictor of academic outcomes. The results of this case study confirm this conclusion in so far as we found strong evidence that collaborative innovation is correlative to not only improved content knowledge but also self-efficacy as a learning outcome (see Figure 3). In this section, we present self-reported evidence that each of the seven student-interns in this case study perceived themselves as becoming more self-reliant and successful in endeavors important to their respective career aspirations.

Although there is a rich research base regarding the concept of self-efficacy as a learning outcome, ${ }^{20,21,22,23}$ it remains a contested construct. ${ }^{23,24}$ Generally, self-efficacy is defined as confidence in an individual's own capacity to execute behaviors necessary to produce specific performance attainments. ${ }^{20}$ For the purposes of this study, we unpack self-efficacy into four interrelated themes that surfaced as being of significant value to the student-interns: ability to 
apply disciplinary content/technical knowledge; confidence in self-directed research and problem solving capability; clearer understanding of potential career pathways; and a new construct, cross-disciplinary sympathy, that describes the transfer of peripheral field-specific knowledge and the ability to use it for improved communication across fields.

Application of content and technical knowledge: Student-interns were able to convey their developing comprehension of systems-level renewable energy generation and energy efficiency during summative assessments, exit interviews, and demonstrations of the testbed in research symposia. In addition, their coordinated contributions of technical tasks enabling the completion of the testbed substantiates enhanced technical proficiency among the interns (refer to the beginning of the "Results" section for a technical description of the testbed). The student-interns themselves recognized and placed value on these accomplishments: "the internship exceeded my expectations as far as knowledge and increasing my technical skills." In the exit interview, a student-intern communicated their post-internship impressions:

"The main thing that we got was exposure...I programmed with the Arduino before, but here we got the hands on and now I am more familiar than I was before... I am more comfortable."

Confidence in process skills: Many respondents cited the experience of working hands-on in groups and the requisite communication as beneficial to their confidence in future endeavors. Tying both themes together, interns expressed the importance of being involved in the design of something new and performing authentic research. This sentiment was predominant in all three assessment instruments, it was not simply that they learned computer programming, but they "designed and processed data" or "designing a circuit to do something for me." The participants explicitly recognized the necessity and value of being an independent thinker and/or researcher; by being challenged by the depth of analysis necessary to design and implement a novel solution, they improved upon their critical thinking and problem solving abilities. Below, an intern reflects on working through the engineering design cycle:

“...it is a bunch of design and 'will this work, no that's not really feasible, let's try again.' There were no instructions for this. We had to design it ourselves and consult with people. 'Will this work? If it doesn't how do we fix it so it does?' That's the greatest thing I got out of this internship-it's the hand on, put the theory to work."

Confidence in career goals: Student-interns related their experiences during the internship with what they perceive as real science and engineering work; that not only proficiency in technical content was necessary to become a professional engineer (for instance), but a strong foundation in scientific process knowledge. Student-interns were supported in adopting roles based on their individual backgrounds, interests, and goals. In doing so, they were able to explore what it meant "if we are gonna become engineers." The two student-interns with no previous ambition to achieve a higher degree both indicated they now feel able to continue their education after their community college experience, while others reflected similar sentiments: 
"This internship was one of the most helpful experiences I have had that not only convinced me of what I wanted to major in, but that I have the ability to do it."

Cross-disciplinary Sympathy: In computer programming, the term "mechanical sympathy" describes a programmer's enhanced ability to deliver high performance solutions by employing an understanding of the mechanics of the hardware and low level frameworks. Here, we adapt and expand on this concept to describe a peripheral knowledge base and the ability to leverage this knowledge to effectively communicate across fields and work towards a multi-faceted solution. The notion of "exposure" to non-primary fields repeatedly surfaced in post-internship discussions and surveys as being beneficial in the achievement of learning goals. The studentinterns described an increased level of comfort and familiarity with the different components of the project; a proposed electrical engineering major stated: "It [the internship] benefited me, I have not really done anything where I get out of the computer and actually wire things and understand the circuit board-to make things talk." When asked what they would remember the most about the internship, an intern responded: "The fact that we were able to learn about how to do so many different things with hands on experience." Through experiencing multidisciplinary group collaboration, student-interns recognized increased competency within themselves in regards to content knowledge to be able to interface as professionals in their respective fields.

"If you can see five or six different ways of how to do something, I feel that that is better than basic understanding about how it works and being stumped on it. If you don't have that background then you just stumble and don't know what to do. In some situations...he [a different major] would see things differently than us engineers."

\section{Discussion of Results}

The results of our analysis confirm that the combination of carefully planned educational scaffolds and strategic facilitation by project mentors were highly conducive to collaborative emergence in the Renewable Energy Summer Internship program and the delivery of an innovative system. It is important, however, to recognize that learner engagement and cohesion within the development teams at this site did not happen spontaneously; rather it was quite deliberately encouraged. Accordingly, we relate participants' ability to engage and move through the process of innovation to their participation in key and carefully planned pedagogical elements of the program design. Figure 3 illustrates the evolution of the innovation process over the internship period. We then present four constitutive processes (choice, challenge, accountability and cross-disciplinary synergy) that we postulate as operational in supporting individual engagement in innovation and correlative to evidence of group- and self-efficacy as learning outcomes (see Figure 4). 


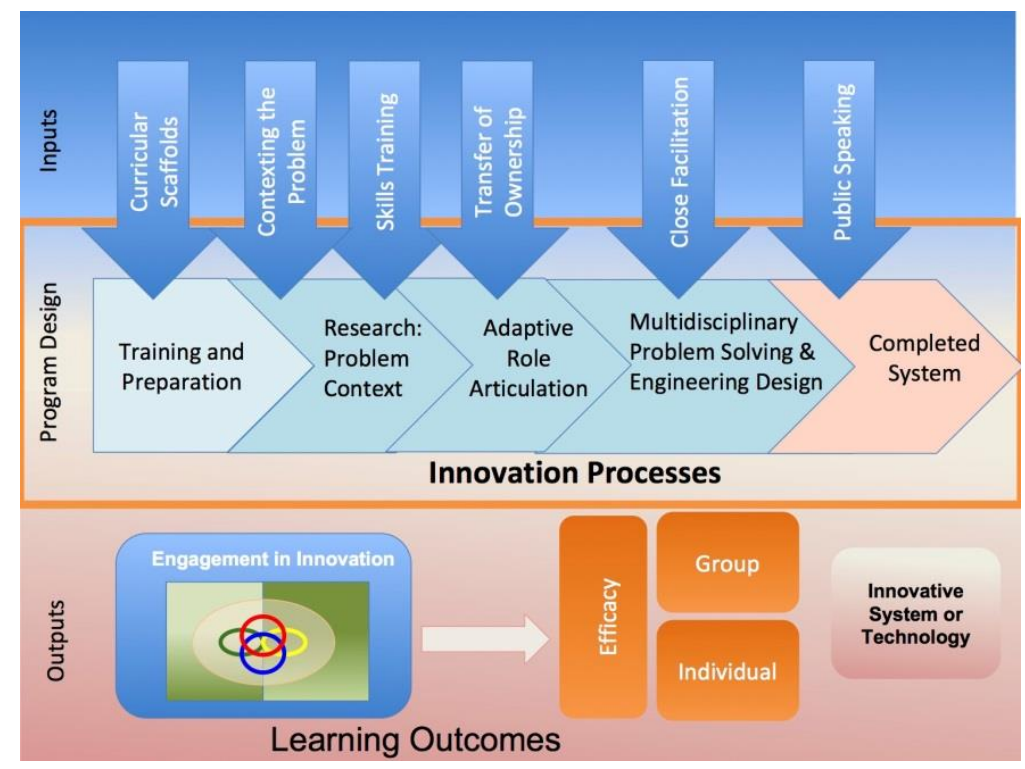

Figure 3: Program design describing the process of innovation and the corresponding learning outcomes on perceived self-efficacy

Each of the vertical arrows illustrated in Figure 3 refer to key educational scaffolds that we have identified as instrumental in moving student-interns through sequential components of the program design. For example, evidence from our data suggests that all of the student-interns involved in the CUSP program perceived that they were working on something truly novel: there was no known solution to the specific problem they were trying solve. This perspective was encouraged by the project mentors who repeatedly and deliberately contexted the proposed problem-solution, the deferrable load testbed, as requiring innovative technology and systemslevel design and potentially may not be feasible. Involving student-interns in the design phase of the project-and on the premise that they would ultimately be reliant on their own design to build an operational deliverable-was a deliberate pedagogical decision. At the conclusion of the internship, each of the participants recognized and valued that they were responsible for not only building and implementing an innovative system, but also for researching and planning the system design. They emphasized that the opportunity to partake in the design phase of a project was critical to the overall quality of their learning and comprehension and unique in their educational career. 


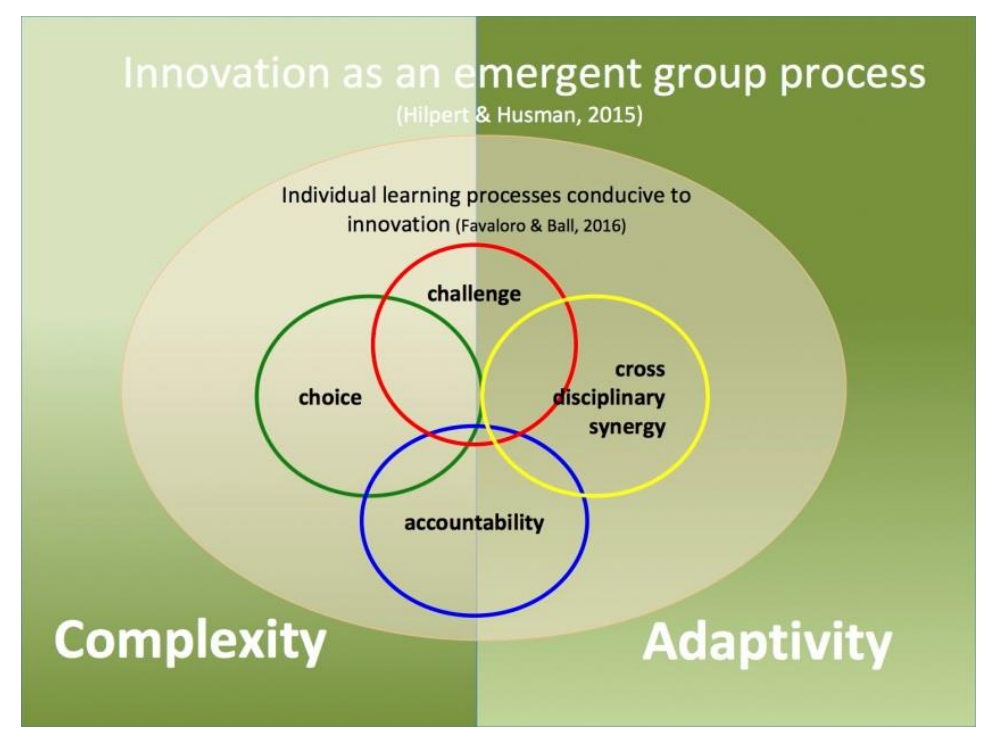

Figure 4: Unpacking emergent innovation in terms of the processes experienced by the individual participant

Figure 4 relates the emergent processes, complexity and adaptivity, to four constitutive constructs (defined below), that we use to explain how individuals in our study succeeded as participants in the innovation process. Although further work is required to validate our assertion, the results of this case study provide preliminary evidence that individuals engaging in any of these four learning processes is predictive of emergent innovation at the group level. In other words, we suspect that learners' involvement in these four processes fosters the development of self-efficacy and thus is conducive to a learner's individual ability to contribute to the group practice of innovation.

Choice: All seven student interns consistently valued the opportunities they were given to make "independent" choices about their responsibilities or roles within the larger project team. They recognized that working through the practice of innovation required technical choices and design decisions that had potential repercussions on the success of the project. The interns expressed a newfound appreciation of how working through these decisions was ultimately foundational to their fuller comprehension of the technical STEM content involved. One student-intern described the importance of choice to his learning process this way:

"The biggest thing I got from this-is being an independent thinker. I was not given a concrete path to follow...I had to decide which data is relevant to take from it. Before I was more guidedsomeone was always forging the path. Here we could still ask for help but we had to be that independent researcher. That is definitely a skill I need to pick up on [not apparent in other previous internships]."

Challenge: Challenge was another consistent theme in our analysis of collected data and can be described as the creative process that interns endured and struggled through when faced with uncertainty or ambiguity about "what to do next" leading to an undetermined result. In hindsight, student-interns recognized that the particular challenges they experienced as part of 
the process of innovation were instrumental in compelling them to take responsibility and be self-directed in their own learning.

"[Designing the testbed] was something that has not been done before, and it's stressful because you have to make decisions and you are held responsible for those decisions and you have to find your way around it. But I feel like it's a challenge that makes you grow up but at the same time I feel like it's as sign of believing in your potential. 'You are not just an intern but I believe that you are capable' and it encourages you to do better. As soon as they said 'We are designing something from scratch 'I said 'ok I am up for it,' I could foresee the challenge of designing something-something that was new."

We argue that the effort involved in overcoming these kinds of challenges is not only inherent to the practice of innovating but an important driver in achieving individual self-efficacy.

Accountability: This was an important theme throughout this study. Student-interns repeatedly described the feeling of being held accountable for their effective execution of tasks to both their group mates and to external stakeholders invested in seeing the testbed completed. Studentinterns recognized that focusing on their own tasks in isolation was insufficient for completing the deliverable. They needed to understand and account for the other group members' and development teams' progress, and reciprocally, they were accountable for producing results that would be compatible with the others' work. The intern responsible for the development of the ancillary logic for control of the smart loads, for instance, required a proactive awareness of the needs and capabilities of the sensor hub programmer in order to effectively co-develop a protocol for data exchange. Accountability emerged as not only important to the participants' interactive engagement within the larger process of innovation, but also as foundational in cultivating an individual sense of ownership for respective scopes of work. We have identified accountability as operational in driving a collaborative solution forward within specifications and thus is a motivator for group and self-efficacy.

Cross-disciplinary synergy: Student-interns regularly evinced sympathetic accumulation of knowledge outside of their own primary training during the internship and in the assessment, as a direct result of peripheral participation ${ }^{25}$ in group-level, multidisciplinary interaction. In reference 17, Hilpert and Husman discuss "collaborative division of labor" as a dimension within the emergence of adaptivity as a group process and argue that group cohesion is implicit of "participation across segments." This construct was valuable in the analysis of interactive engagement of the individual participants of our own study; group dynamics characterized by a strong division of labor and increased role differentiation position learners for "legitimate peripheral participation.” Juan described his experience with members of his development team in this way:

"I am kinda sorta in between the two [teammates], since both of them they don't have too much programing experience, but they are helping me find out things that we need to work on ... and on the way they learn a little bit of programming...and I learn [a little bit of what they know]." 


\section{Conclusions and Future Work}

The design of the deferrable load testbed required penetrating yet adaptive collaborations across multiple disciplines and diverse backgrounds. We found that in many ways, it was precisely the multidisciplinary nature of this problem-solving activity that was instrumental in creating the opportunities for choice, challenge, accountability and cross-disciplinary synergy that in turn motivated the successful delivery of innovation. From a broad perspective, the results of this study were not at all surprising: student-interns immersed in an intensive program on engineering-design experienced collaborative innovation to a much greater extent than the average experience of students in formal engineering classroom and laboratory settings. The importance of this study is the revelation of the contextual conditions, instructional strategies, and constitutive learning processes that were conducive to not only group-efficacy in achieving the intended outcome but also to self-efficacy that individual learners require to be successful in STEM educational and career pathways. Diversity in experience and backgrounds seemed to enhance many of these learning outcomes; as such, future internships should actively encourage more diverse participation. Consequently, we need to examine our outreach strategies to better understand how to engage a more gender diverse student body.

Many of the conclusions of this study are tentative with limited statistics; validating them will require future work and more rigorous application of assessment tools with sufficient respondents to establish statistical significance. It is also important to recognize that the program design presented here may not be directly implementable in a classroom context. A high mentorto-learner ratio is needed to sustain the close supervision and responsive facilitation essential to productively moving novices through indeterminate problem-solving activities (in this case, two mentors per seven students). Furthermore, this case study and past work suggest learners with less formal training may require even closer facilitation; the high school student alone expressed frustration in the "aloof guidelines" of this internship. One implication is to find ways to incentivize students and instructors to include these opportunities in normative practice earlier on, perhaps as shorter learning modules. The individual components articulated in this program design can be utilized to scaffold activities around specified learning outcomes within the time constraints and logistics of a classroom setting. Further research is needed to determine the feasibility and validity of employing the individual activities over successive class meetings in a formal course structure, rather than as an intensive experience

Finally, a comprehensive review of the literature on self-efficacy and related constructs, such as "ownership," "self-determination theory," "intrinsic motivation," "learning autonomy," etc. is required to further examine the utility of the four processes we have presented here and link them as generative to the themes comprising self-efficacy. This literature review would additionally inform the adaptation of survey items and prompts used in successive audio recordings to directly target an investigation of these constructs. Taken together, the larger implementation of the adapted survey and audio-diary instruments in complement with the literature review would 
provide a more rigorous framework for future study into the processes conducive of an individual learner's contribution to innovation.

\section{Acknowledgements}

This work has been supported by a Title IX grant from the United States Department of Education to Hartnell Community College, supporting the "STEM Regional Community College-to-University Success Program” under award No. P031C110068. We also acknowledge the commitment and effort maintained by supportive staff at Hartnell: Daniel Orr, Brenda Jones, and Tito Polo. Our appreciation also goes out to the students for their enthusiasm and patience throughout the internship.

\section{References}

1(2015) National Solar Jobs Census 2014. The Solar Foundation, available at:http://www.thesolarfoundation.org/national-solar-jobs-census-2014/. Accessed

2(2015) Fact Sheet: Jobs in Renewable Energy and Energy Efficiency Environmental and Energy Study Institute http://www.eesi.org/papers/view/fact-sheet-jobs-in-renewable-energy-and-energy-efficiency-2015

3 (2008) Skills needs in the energy industry. A report on the initial findings of the three surveys conducted by the Energy Institute, Deloitte and Norman Broadbent

4 (2013) Renewing futures: A National Human Resources Strategy for Renewable Electricity. Electricity Human Resources Canada

5 (2009) Task Force on America's Future Energy Jobs. National Commission on Energy Policy

6 DuPuis, E. M., \& Ball, T. (2013). How not what: teaching sustainability as process. Sustainability: Science, Practice, \& Policy, 9(1).

7 Wertsch, J. V. (1998). Mind as action. New York, NY: Oxford University Press.

8 Cole, M., \& Engeström, Y. (1993). A cultural-historical approach to distributed cognition. Distributed Cognitions: Psychological and Educational Considerations, 1-46.

9 Engeström, Y. (2014). Learning by expanding. Cambridge University Press

10 Aclufi, A., Biological Sciences Curriculum Study., \& National Institute of General Medical Sciences (U.S.). (2005). Doing science: The process of scientific inquiry. Colorado Springs, CO: BSCS.

11 Hofstein, A., \& Lunetta, V. N. (2004). The laboratory in science education: Foundations for the twenty-first century. Science Education, 88(1), 28-54.

12 Petersen, S. “The General Practice of Engineering Notes" Unpublished

13 (2015, June) California Independent Systems Operator (ISO) website: http://www.caiso.com/Pages/TodaysOutlook.aspx 
14 Douglass, P. J., Garcia-Valle, R., Nyeng, P., Østergaard, J., \& Togeby, M. (2011, December). Demand as frequency controlled reserve: Implementation and practical demonstration. In Innovative Smart Grid Technologies (ISGT Europe), 2011 2nd IEEE PES International Conference and Exhibition on (pp. 1-7). IEEE.

15 Douglass, P. J., Garcia-Valle, R., Nyeng, P., Ostergaard, J., \& Togeby, M. (2013). Smart demand for frequency regulation: Experimental results. Smart Grid, IEEE Transactions on, 4(3), 1713-1720.

16 Kondoh, J., Lu, N., \& Hammerstrom, D. J. (2011, July). An evaluation of the water heater load potential for providing regulation service. In Power and Energy Society General Meeting, 2011 IEEE (pp. 1-8). IEEE.

17 Hilpert, J. C., \& Husman, J. (2015, June), A Group-level Framework for Emergent Properties of Interactive Learning. Paper presented at 2015 ASEE Annual Conference and Exposition, Seattle, Washington. $10.18260 /$ p.23391

18 Hilpert, J. C., Husman, J., Stump, G. (2015) A manual for the Use of the Innovative Engagement Scale (IES). Unpublished (personal communication )

19 (2016, Jan) ABET, Criteria for Accrediting Engineering Programs. http://www.abet.org/accreditation/accreditation-criteria/criteria-for-accrediting-engineering-programs-20162017/\#outcomes

20 Bandura, A. (1977) Self-efficacy: Toward a unifying theory of behavior change. Psychological Review, 84, pp. $191-215$

21 Zimmerman, B. J. (2000). Self-efficacy: An essential motive to learn. Contemporary educational psychology, 25(1), 82-91.

22 Betz, N. E. (2013). Assessment of Self-Efficacy. Geisinger, K. F., et.al. (Eds.). APA handbook of testing and assessment in psychology, Vol. 2: Testing and assessment in clinical and counseling psychology. APA handbooks in psychology., (pp. 379-391). Washington, DC, US: American Psychological Association.

http://dx.doi.org/10.1037/14048-022

23 Bandura, A. (1994). Self-efficacy. John Wiley \& Sons, Inc..

24 Jernigan, C. G. (2004). What do students expect to learn? The role of learner expectancies, beliefs, and attributions for success and failure in student motivation. Current Issues in Education, 7(4).

25 Lave, J., \& Wenger, E. (2009). Legitimate Peripheral Participation in Communities. Strategic Learning in a Knowledge Economy, 167. 